\title{
DIGLOSIA LANGUAGE IN DRUG SERVICES AT THE PHARMACY ANWAR MEDIKA SIDOARJO HOSPITAL
}

\author{
Suwito ${ }^{1}$ \\ STIKES RS. Anwar Medika, \\ Corresponding Author: ${ }^{1}$ ahmadsuwito7@gmail.com
}

\begin{abstract}
Communication is a drug service in pharmacy because of its activities as speakers and speech partners because basically communication between speakers and speakers is a sociolinguistic field. The events that occur in language contact carried out by speakers and speech partners at drug services in pharmacies do not occur in a language diglossia. The research objective was to determine the language diglossia in anwar Medika hospital pharmacy. This research uses descriptive qualitative method. Where researchers are placed as the key. Data discussion is done by reducing data, presenting data and drawing a conclusion. The result of the discussion based on Data A is a sentence uttered by a speaker delivered in communicative language that is easy to understand. The answer of a diapotek buyer does not use Indonesian as discussed by the waiter, but speaking in krama alus, generally using Javanese has the best position. Data B, does not use a variety of speeches and interlocutors, because they are the same age in health services to the buyer to convey in smooth, clear and easy to understand language and so that the interlocutor answers in a short language. Data $\mathrm{C}, \mathrm{a}$ conversation with their servants explained in detail, and was understood. The greeting sentence that is always spoken proves the existence of a person speaking to.
\end{abstract}

Keywords: Communication, Diglossia,, pharmacy

\section{DIGLOSIA BAHASA DALAM PELAYANAN OBAT DI APOTEK RUMAH SAKIT ANWAR MEDIKA SIDOARJO}

\begin{abstract}
Abstrak
Komunikasi merupakan sebuah pelayanan obat pada farmasi karena kegiatanya sebagai penutur dan mitra tutur karena pada dasarnya komunikasi antara penutur dan mitratutur merupakan bidang sosiolinguistik. Peristiwa yang terjadi dalam kontak bahasa yang dilakukan oleh penutur dan mitra tutur pada pelayanan obat di apotek karena tidak terjadi pada sebuah diglosia bahasa. Adapun tujuan penelitian adalah untuk mengetahui diglosia bahasa di apotek rumah sakit anwar medika. Penelitian ini menggunakan metode kualitatif deskriptif. Dimana peneliti ditempatkan sebagai kunci. Pembahasaan data dilakukan dengan reduksi data, penyajian data dan penarikan sebuah simpulan. Hasil pembahasaan yang berdasarkan pada Data A adalah sebuah kalimat diucapkan oleh penutur disampaikan dengan bahasa yang komunikatif yang mudah dipahami. Jawaban seorang pembeli diapotek tidak menggunakan bahasa Indonesia seperti yang dibicarakan pelayan, tetapi melakukan tuturan bahasa krama alus pada umumnya penggunan bahasa jawa mempunyai kedudukan yang paling baik. Data B, tidak mengunakan sebuah ragam tuturan dan lawan tutur, karena mereka usianya sama dalam pelayanan kesehatan kepada pembeli menyampaikan dengan bahasa yang halus, jelas dan mudah dimengerti dan sehingga lawan bicara menjawab bahasa yang singat. Data $\mathrm{C}$, sebuah perbincangan dengan para pelayan mereka menerangkan secara terperinci detail, dan dipahami. Kalimat sapaan yang selalu diucapkan, membuktikan keberadaaan sebuah lawan bicara.
\end{abstract}

Kata Kunci: Komunikasi, Diglosia,farmasi 


\section{PENDAHULUAN}

Bahasa sebagai segala bentuk komunikasi yang diucapkan di mana pikiran seseorang dapat disimbolisasikan agar dapat menyampaikan arti kepada orang lain. Pelaksanaan Kegiatan dalam layanan kefarmasian diapotek sangat memerlukan bahasa sebagai alat komunikasi antara penutur dan mitratutur. Komunikasi yang terjadi antara pelayan dan pembeli ini terjadi sebuah diglosia dalam sebuah bahasa. Dengan bahasa yang baik, kegaitan pelayanan obat di apotek rumah sakit anwar medika berjalan dengan baik. Proses terjadinya sebuah tuturan berkomunikasi dalam pelayanan kefarmasian di apotek yang melibatkan penutur dan mitra tutur merupakan sebuah proses komunikasi bahasa yang pada intinya masuk ke sebuah ranah sosiolingusitik. Dalam bidang sosiolinguistik masyarakat merupakan sebagai subyek tutur mempunyai kegiatan yang sangat penting dalam penggunaan Bahasa karena dengan bahasa yang terjadi antara pelayan dan pembeli tercipata sebuah bahasa yang komunikatif.

Penggunaan dalam komunikasi pada sebuah bahasa yang terjadi antara penutur

\section{METODOLOGI PENELITIAN}

Dengan metode kegiatan penelitian yang digunakan dengan metode kualitatif. Mengenai jenis penelitian ini menggunakan deskriptif kualitatif yaitu mendiskripisikan sebuah penelitain dengan diglosia bahasa yang terjadi dan mitratutur pada sebuah pelayanan diapotek rumah sakit anwar medika. Karena dengan bahasa yang komunikatif akan terjadi sebuah tuturan yang mudah dimengerti dengan adanya kejadian kontak bahasa yang terjadi pada penutur dan mitratutur pada penjual yang ada di apotek anwar medika tidak bisas lepas dari diglosia bahasa. Sebuah diglosia terjadi terdapat suatu bahasa dimana terdapat pembagian yang sepada dengan varian bahasa pada masyarakat. Dalam pratiknya penggunaan bahasa pada pelayanan apotek dimana saja selalu mengalami diglosia bahasa yang dapat terjadi anatra penutur dan mitratutur..

Pelayan apotek kefarmasian di rumah sakit anwar medika sangat bagus karena menarik untuk dijadikan penelitian lebih lanjut karena dengan penelitian pada diglosia bahasa pelayanan apotek sangat penting untuk dijadikan penelitian. Penelitin ini dilakukan di apotek rumah sakit anwar medika sidoarjo dijadikan sebagai objek penelitian. Karena dengan rumusan masalah: Bagaimanakah bentuk sebuah komunikasi diglosia pelayanan diapotek rumah sakit anwar medika.

antara penjual dan pembeli pada pelayanan obat diapotek rumah sakit anwar medika.

Dalam penelitian ini yang menggunakan sebuah metode penelitian kualitatif. Adapun jenis penelitian ini menggunakan deskriptif, yaitu dengan mendeskripsikan 
(menggambarkan) populasi yang diteliti pelayan diapotek menyampaikan dengan yakni diglosia bahasa dalam pelayanan obat di bahasa yang informatif dengan penggunaan apotek Rumah Sakit Anwar Medika Sidoarjo.

Dari hasil penelitian ini terdapat beberapa fase yang pertama dengan reduksi data,yang kedua dengan penyajian dan terakhir yaitu penarikan kesimpulan. Ini berarti data-data yang diberikan dapat memberikan sebuah analisa sehigga dapat diambil menjadi simpulan yang baik

\section{HASIL PENELITIAN}

Hasil dari perbincangan di antara penjual dan pembeli di apotek rumah sakit anwar medika sidoajo.

Dari data A:

\section{Konteks pembicaraan:}

Ada seorang ibu-ibu ingin datang keapotek rumah sakit anwar medika, asisten apoteker menyerahkan obat yang ibu beli dan sambil menjelaskan waktu dan cara minum.

\section{Pelayan:}

"Bu minumnya sehari satu kali ya, sesudah makan diminum obatnya, ini obat vitaminnya sehari tiga kali bu yah, minumnya sesudah makan. Bu ini obat nya diminum sekali bu yah"

Pembeli: "Nggeh bu".

Dari hasil percakapan diglosia dalam pelayanan diapotek adalah dalam pembicaraan tersebut dapat diinformasikan kepada seorang ibu yang berusia 48 tahun mengunjungi apotek di anwar medika dan disambut oleh asisten apoteker dengan diberi informasi ketika penggunaan obat sambil menyerahkan obat. Seorang yang menjadi sebuah bahasa Indonesia yang komunikatif dan bahasa yang mudah di pahami dalam kehidupan sehari-hari. Kalimat yang diucapkan oleh pelayan disampaikan dengan bahasa yang normatif. Kata "Bu yah" ini menginformasikan dengan kata sapaan yang diperkuat dengan lawan tutur. Dengan lawan bicara yang merasa dianggap keberadaanya dan sangat di hormati kehadiranya karena ada komunikasi anatara ibu dan pelayan apotek.

Dari kata yang ucapkan oleh pelayan apotek tersebut dengan jawaban "Nggeh". Jawaban ini bukan menggunakan bahasa indonesia melainkan menggunakan bahasa jawa yang mempunyai kedudukan yang paling tinggi yaitu bahasa krama Inggil yang artinya bahasa penghormatan kepada pelayanan apotek anwar medika sidoarjo. Dengan kalimat yang berdasarkan jawaban bahasa jawa tersebut mempunyai kedudukan yang paling tinggi dalam menghargai dan menghormati sesorang yang ungkapka dengan sebuah bahasa jawa.

Data B:

Konteks:

Seorang pemuda sedang menerima pembeli obat diapotek rumah sakit anwar medika sidoarjo.

\section{Pelayanan:}

"Bu minum obat nya Tiga kali sehari setelah makan"(sambil menunjukan obat)". 


\section{Pembeli:}

"Iya bu terima kasih ya"

\section{Pelayan:}

"Jangan lupa minum Tiga kali sehari setelah makan, terima kasih juga bu".

Hasil dari percakapan diatas pembicaraan tersebut pelayan diapotek Anwar Medika memberikan informasi secara lansgung kepada pembeli tentang ajuran dalam penggunaan obat tanpa kata sapaan. Pembeli memiliki usia yang sama-sama muda hanya menjawab "Iya" Memberitahukan kepada pembeli sudah paham apa yang dimaksud oleh pelayanan tanpa ada jawaban selajutnya. Dari hasil tuturan ini tidak ada ragam karena mereka masih sama-sama muda. Karena bahasa yang disampaikan kepada penjual terbilang singkat tanpa ada pertanyaan yang lain. Sebuah tanggapan pembeli memberikan penjelasan karena pembeli terkesan biasa tanpa memberikan penghargaan terhadap pelayan hal ini menunjukan bahwa percakapan yang dilakukan kepada teman sejahwat dengan keingginan tidak ada unsur tuturan antara pelayan dan penbeli karena pada dasarnya ragam tuturan diglosia karena pada dasarnya ragam bahasa diglosia ini merupakan sebuah tuturan bahasa.

Data C:

Konteks:

Seorang nenek mengujungi apotek untuk mengambil obat karena pelayanan langsung dengan menyerahan obat dan pelayan memberikan penjelasanya penggunaanya.

\section{Pelayan:}

"Sehari sekali harus ditensi ya bu, sesudah makan. Sehari sekali gulanya di kurangi harus banyak makan yang bergizi. Yang ini sehari dua kali buat lambung agar lambung tidak sakit diminum sesudah makan tiga kali" Pembeli:

"Pokoknya minum obatnya harus sesudah makan nggeh bu jangan lupa”.

Analisa dalam diglosia percakapan diatas menunjukan pelayan menjelasakan secara detal, ramah dan sangat komunikatif dan mudah dipahami. Dengan kalimat sapaan yang diutarakan berulang-ulang dalam penggunaan sapaan, menunjukan mengakui keberadaan sebuah lawan bicara. Kata-kata yang disampaikan meruapakan penegasan agar bisa di mengerti oleh pembeli seperti "Ya $\mathrm{Bu}$ Yah. Hal ini menunjukan pelayan ketika menyampaikan secara sadar karena dengan penggunan obat yang disampaikan. Karena dari hasil tuturan pembeli menjawab"Pokoknya sebelum dan sesudah nggeh?. Jawaban tersebut merupakan jawaban sebuah penegasan. Bahwa pembeli sudah jelas apa yang disampaikan oleh pelayan apotek rumah sakit anwar medika. Sebuah kata yang diucapkan "Pokoknya" merupakan simpulan dari apa yang disampaikan oleh pelayan dengan jawaban tersebut menghargai kepada pelayan apotek. Dari perbicangan yang sudah dijelaskan bahwa tuturan tersebut menggunakan ragam diglosia bahasa tidak mudah bias karena 
bahasa yang disampaikan anatara pembeli dan pelayan apotek menggunakan bahasa sehari-hari antara bahasa indonesia dan bahasa daerahnya hal ini menunjukan ragam

\section{SIMPULAN}

Dari data yang sudah diambil pada data A Jawaban seorang wanita tua sebagai pembeli tidak memakai bahasa Indonesia seperti yang diberitahukan kepada pelayan obat diapotek, tetapi pembeli tersebut memakai bahasa Jawa dengan bahasa paling halus yaitu kromo inggil karena dalam bahasa jawa kromo inggil mempunyai kedudukan yang paling tinggi yang paling sopan dalam etika berbicara pada masyarakat Jawa. Dari hasil Jawaban pembeli tersebut merupakan penghargaan kepada pelayan yang dihormati karena dalam bahasa jawa biasanya orang yang menggunakan tuturan bahasa jawa pada tingkatan paling tinggi akan di hormati. Pada data B yang dapat disimpulkan ketika pembeli terkesan bisasa karena tidak ada penghargaan tinggi terhadap pelayanan yang ada di obat apotek hal ini memberitahukan bahwa sebuah percakapan ketika dilakukan dengan sejawat diglosia selalu digunakan pada sebuah penutur dan mitra tutur.

atau sama-sama muda cenderung ragam bahasa yang diperoleh tidak mengalami sebuah tuturan diglosia berbahsa yang yang diinginkan pada tuturan dan lawan tutur.

Pada data $\mathrm{C}$ yang dapat dijelaskan pada sebuah kalimat "Pokoknya Ibu sebelum dan sesudah nggeh". Jawaban dari percakapan ini merupakan sebuah kalimat memberi penjelasan bahwa seorang pembeli sudah sangat jelas terhadap apa yang disampaikan kepada pelayan. Sebuah kata "Pokoknya" merupakan simpulan dari apa yang disampaikan karena jawaban dari pembeli sangat menghargai dan memberikan hormat dengan menggungkapkan kata" Nggeh" sebagai kalimat tuturan dalam bahasa jawa yang sangat baik yang diberikan kepada orang yang dihormatinya. Dari hasil percakapan ini memberitahukan bahwa diglosia bahasa tidak bisa lepas dari percakapan sehari-hari sebagai manusia yang bermakluk sosial dan berbudaya ragam bahasa. 


\section{DAFTAR PUSTAKA}

Alwasilah.A.Chaedar.1990. Sosiologi Bahasa. Bandung: Angkasa.

Chaer, Abdul dan leonie Agustina. 2004. Sosiolinguistik. Jakarta: Rineka.

Fishman,J.A.1972. Language and Nationa lism:Two Integrative Essays, Rowley.M.A: Neury Haouse.

Nababan. 2004. Sosiolinguistik Suatu Pengantar.Jakarta: Gramedia Pustaka Utama.

Moloeng,Lexy j.2004. Metode Penelitian Kualitatif. Bandung: PT Remaja Rosda.

Ruslan, Rosady.2002. Kiat dan Strategi Kampaye Public Relations. Jakarta: PT Raja Grafindo.

Sumarsono.2007.Sosiolinguistik. Yogyakarta: Sabda.

Rian, Bambang.2004.'Bahasa Jawa Sarat Etika dan Moral" dalam kedaulatan Rakyat, selasa 11 Mei 2004.

Paina dan Sumarsono. 2004. Sosiolinguistik. Yogyakarta: Sabda. 
Jurnal DISASTRI (Pendidikan Bahasa dan Sastra Indonesia)

Volume 2, Nomor 3, Desember 2020| P-ISSN : 2716-4114 | E-ISSN: 2722-3329 